\title{
Congenital Hyperthyroidism: The Fetus as a Patient
}

\author{
Michel Polak ${ }^{a, b}$ Isabelle Legac ${ }^{b}$ Edith Vuillard ${ }^{c}$ Jean Guibourdenche ${ }^{c}$ \\ Mireille Castanet $^{\mathrm{a}}$ Dominique Luton $^{\mathrm{c}}$

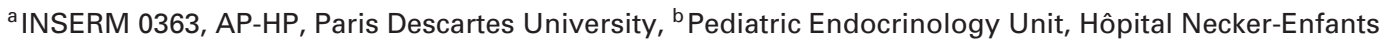 \\ Malades, ${ }^{\mathrm{C}}$ Department of Perinatalogy, Multidisciplinary Center for Prenatal Diagnosis EA3102, \\ Robert Debré Hospital, Paris, France
}

\section{Key Words}

Congenital hyperthyroidism $\cdot$ Fetal medicine $\cdot$ Goiter .

TSH receptor $\cdot$ Fetus $\cdot$ Ultrasonography $\cdot$ Thyroid

hormone $\cdot$ Graves'disease $\cdot$ Thyroid stimulating

immunoglobulins

\begin{abstract}
Congenital hyperthyroidism is less frequent than congenital hypothyroidism but its impact on growth and development can be as dramatic. The immune form of hyperthyroidism that is transmitted from a mother with Graves' disease to her foetus and then neonate is transient, but cases of persistent congenital hyperthyroidism had also been described, that can now be explained by molecular abnormalities of the thyrotropin receptor. The abundance of published data on the neonatal effects of maternal Graves' disease contrasts with the paucity of information on fetal effects. Recent studies showed that it is of utmost to scrutinize fetal thyroid by expert ultrasonographist and to have a team work with obstetricians and pediatric endocrinologists in pregnant women with Graves' disease. This allowed to accurately determine the fetal thyroid status and to adapt the treatment in the mothers successfully. Fetal hyperthyroidism does exist and needs an appropriate aggressive treatment. Clearly the fetus has become our patient!
\end{abstract}

\section{KARGER}

Fax +4161306 1234 E-Mail karger@karger.ch www.karger.com

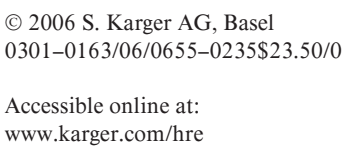

Congenital hyperthyroidism is less frequent than congenital hypothyroidism but its impact on growth and development can be as dramatic. Exposure of the conceptus to excess thyroid hormone throughout gestation results in fetal loss and in decreased birth weight of the surviving newborns [1], severe congenital hyperthyroidism from activating mutations in the thyrotropin receptor gene occurring de novo in the fetus may lead to mental deficiency [2] and fetal hyperthyroidism from maternal Graves' disease may lead to fetal death $[3,4]$.

\section{Normal Thyroid Gland Function}

The thyroid gland develops from a midline thickening of the pharyngeal floor and paired caudal extensions of the fourth pharyngobranchial pouches $[5,6]$. In the human fetus, at 7 weeks of development, these structures have fused and the thyroid gland has migrated to its definitive position in the anterior neck. Thyroid follicular cells constitute the major cellular component of the thyroid and become organized in a structure made of a single layer of polarized cells surrounding a colloid-containing lumen, the thyroid follicle. From the functional standpoint, the thyroid can be envisioned as a structure that extracts and concentrates the iodine that reaches the gland through the bloodstream to convert it into thyroxine $\left(\mathrm{T}_{4}\right)$ and triiodothyronine or $\mathrm{T}_{3}$. Under normal cir-

Prof. Michel Polak MD, PhD, Service d'endocrinologie pédiatrique INSERM EMI 0363, Hôpital Necker Enfants-Malades, 149, rue de Sèvres FR-75015 Paris (France)

Tel. +33144494802 or +33144494803, Fax +33144381648

E-Mail michel.polak@nck.ap-hop-paris.fr 
Table 1. Fetal and neonatal hyperthyroidism

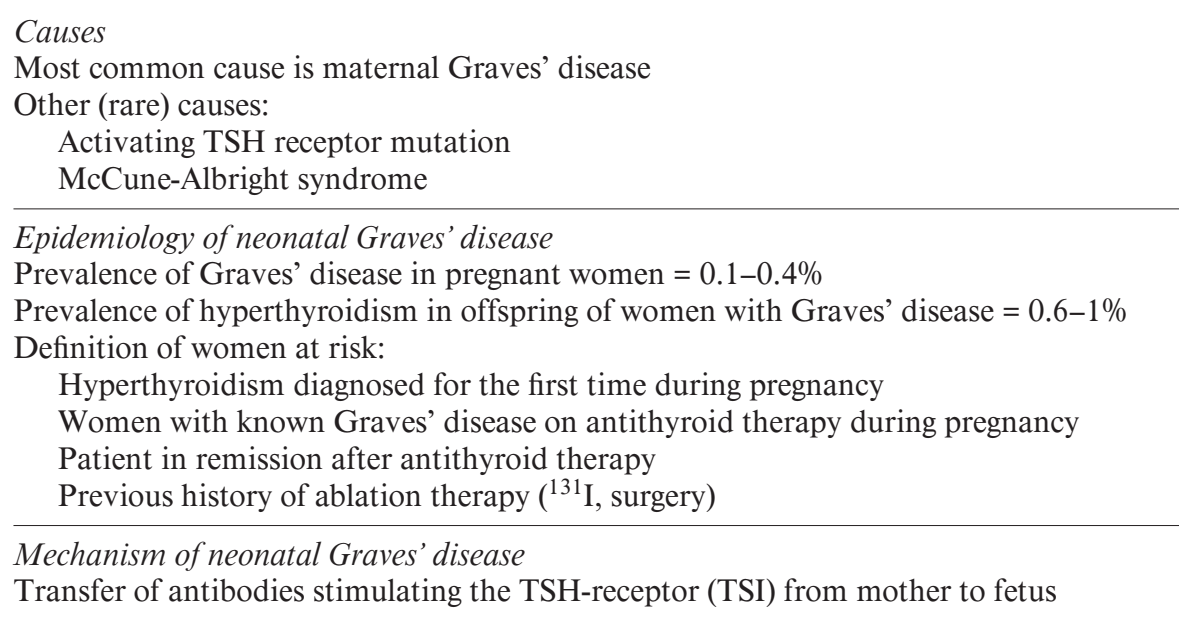

cumstances, the thyroid secretes about $80 \% \mathrm{~T}_{4}$ and $20 \%$ $\mathrm{T}_{3}$ and also secretes thyroglobulin. Thyroid hormone synthesis is primarily regulated by the availability of iodine in the environment and by pituitary thyrotropin (TSH) that acts on its receptor (the TSHR) to stimulate the proliferation, differentiation and function of the thyroid follicular cells. At 10 weeks of development, thyroid hormone synthesis begins [7-9]. Functionally, the fetus progresses from a state of both primary (thyroidal) and tertiary (hypotalamic) hypothyroidism at midgestation through a state of mild tertiary hypothyroidism during the final weeks of pregnancy to fully mature thyroid function in the perinatal period. Even if the development and maturation of the fetal thyroid function is relatively independent from the one of the mother, transplacental passage from mother to fetus take place, specially of iodine and T4, throughout gestation [10]. This maternal contribution to fetal thyroxine, not $\mathrm{T} 3$, concentration is important for normal maturation of the fetus and of utmost importance for his neuronal development [11].

\section{Perinatal Hyperthyroidism}

Fetal and neonatal hyperthyroidism has mostly been described in the context of maternal Graves' disease (table 1). It has been estimated that about $0.2 \%$ of pregnant women have Graves' disease; however, only $1 \%$ of children born to these women are described as having hyperthyroidism [12]. Therefore, overt neonatal hyperthyroidism is rare and concerns only one neonate out of 50,000
In addition to this immune form of hyperthyroidism that is transmitted by the mother but is transient, cases of persistent congenital hyperthyroidism had also been described, some with an apparently dominant pattern of inheritance. Most of these cases can now be explained by molecular abnormalities of the thyrotropin receptor [13].

\section{Pathogenesis of Congenital Hyperthyroidism}

\section{Transfer of Maternal Antibodies: Transient}

\section{Congenital Hyperthyroidism}

In most cases, the disease is due to thyroid stimulating immunoglobulins (TSI) which are transferred from the maternal into the fetal compartment, leading to stimulation of the fetal thyroid by activation of the TSH receptor. This leads to an increase in thyroid hormone secretion, and as a consequence, to thyrotoxicosis first in utero and then postnatally until the maternal antibodies have disappeared from the infant's circulation [14], which occurs at the latest by 4 months of life. The fetal thyroid gland starts secreting thyroid hormone at about 10 weeks of gestation; the TSH receptor starts responding to the stimulation of TSH and therefore to the stimulation by TSI during the 2nd trimester of gestation. The fetal concentration of IgG-type immunoglobulin, in particular TSI, is low at about the 15 th week of gestation, and increases progressively to reach the maternal level at around the 30th week of gestation. As there is a certain degree of correlation between an elevated level of transmitted antibodies and the appearance of thyrotoxicosis, fetal hyperthyroidism develops during the 2 nd half of gestation mostly in women with high levels of TSI [14]. 
TSH receptor-blocking antibodies may also be present in pregnant women with Graves' disease. Their transplacental passage from mother to fetus has been demonstrated [15], and the signs that result in the fetus are due to the balance between the stimulating action of the TSI and the inhibitory action of the TSH receptor-blocking antibodies.

\section{Constitutive Activation of TSH Receptor Signaling: Persistent Congenital Hyperthyroidism}

An even more uncommon type of neonatal hyperthyroidism was initially described as dominantly transmitted Graves' disease with persistence of hyperthyroidism years after a neonatal onset [16]. It was subsequently realized that markers of autoimmunity were generally lacking in these cases [17]. Another decade later, dominantly inherited mutations resulting in an increase in the constitutive activity of the TSH receptor were shown to be responsible for this phenotype [18]. Subsequently, the same mechanism occurring de novo was identified in neonates with severe persistent non-autoimmune hyperthyroidism $[2,19]$. In McCune-Albright syndrome, which results from activating mutations in $G N A S$, the gene encoding the alpha subunit of the stimulatory $G$ proteins, cases presenting with neonatal hyperthyroidism have been reported [20,21].

In 5 kindreds with familial congenital non-autoimmune hyperthyroidism due to germline activating mutations of the TSH receptor, Leclère et al. found that 49 out of 120 subjects examined were hyperthyroid. Remarkably, women were affected more frequently in this series ( 32 women vs. $17 \mathrm{men}$ ). The onset of thyrotoxicosis was early, but varied from 1 to 23 years, depending on the family. Interestingly, a systematic screening of the families identified two children with decreased TSH but no signs of hyperthyroidism, emphasizing the possibility of detecting affected children before the appearance of the disease and its potential deleterious consequences. The goiters were homogeneous in children but tended to become multinodular later in life. No ophthalmopathy was detected and this was an important diagnostic criterion. No circulating antithyroid antibodies, including antiTSH-receptor antibodies, sought by binding or functional assays, were detected in these patients. Recurrence after antithyroid drug (ATD) therapy, non-ablative radioiodine treatment or partial thyroidectomy was frequent. Pathological studies of thyroid glands were distinct from those of autoimmune Graves' disease, because no mononuclear cells infiltrated the thyroid and none of the usual markers of Graves' were present on immunohistological examination [22]. The diagnosis of non-autoimmune hyperthyroidism with thyroid hyperplasia should be considered in the presence of a family history of thyrotoxicosis, a high incidence and early occurrence of the disease, moderate and diffuse goiter (only in young people and not in the case of recurrence), absence of extrathyroidal signs of Graves' disease (although proptosis should not be an exclusion criterion), absence of circulating thyroid antibodies, recurrence after medical treatment or after non-ablative surgical or radioiodine treatment.

Sporadic congenital non-autoimmune hyperthyroidism with thyroid hyperplasia due to de novo mutations of the TSH receptor gene have also been described $[2,19]$. Interestingly, the mutations found in these cases are also found in toxic adenomas, whereas those found in familial cases are 'private'. This may suggest a historical bias due to the fact that these private mutations are milder and would not significantly decrease reproductive fitness [23]. By contrast, the sporadic cases are so severe that they probably did not survive before the advent of modern treatments for neonatal thyrotoxicosis. These severe cases who have developmental delay also emphasize the potentially deleterious effect of fetal hyperthyroidism, independently of the presence of craniostenosis and/or microcephaly $[2,17,19]$. Finally, one case of a somatic activating mutation in the extracellular TSH-binding domain of the TSH receptor has been reported in a male infant with congenital hyperthyroidism due to a toxic adenoma [24].

In conclusion, constitutive activation of TSH signaling due to mutations in TSHR or GNAS is a possible, although rare, etiology of persistent neonatal hyperthyroidism, which may develop during fetal life. It should be suspected in the absence of maternal signs of thyroid autoimmunity.

\section{Clinical Presentation of Congenital Hyperthyroidism}

Fetal hyperthyroidism may be suspected because of intrauterine growth retardation and fetal tachycardia. Premature birth is frequent. In contrast to Graves' disease in older children, the neonatal form affects both sexes equally. The clinical signs of hyperthyroidism generally appear or are only noticed several days after birth. This is due to the ATD given to the mother, which are transferred across the placenta and control the fetal hyperthyroidism. As soon as the ATD disappears in the newborn (which takes only a few days), the newborn thyroid is no longer blocked, and the TSIs, which have a 
Table 2. Clinical signs present at diagnosis in ten neonates with hyperthyroidism (nine autoimmune cases and one case due to a neomutation in the TSH receptor) [12]

Tachycardia (can lead to heart failure)
Goiter
Hyperexcitability
Poor weight gain (despite $\uparrow$ appetite)
Hepatomegaly and/or splenomegaly
Stare and/or eyelid retraction
Bilateral gynecomastia
Cardiac insufficiency

$10 / 10$

$7 / 10$

$7 / 10$

$5 / 10$

$5 / 10$

$5 / 10$

$2 / 10$

$1 / 10$

Intrauterine growth retardation, premature birth, vomiting, diarrhea, fever, tachypnea, jaundice, thrombocytopenia and advanced skeletal maturation have been described in other infants.

longer half-life than the ATD, lead to an increase in thyroid hormone production and therefore to overt clinical hyperthyroidism. As during fetal life, if both TSH-receptor blocking antibodies and TSIs are present in the neonate, euthyroidism may ensue.

The clinical signs vary in severity (table 2) and it is likely that some neonates born to mothers with autoimmune hyperthyroidism have very transient hyperthyroidism that is not detected. Hyperexcitability, increased appetite but poor weight gain, vomiting or diarrhea, fever with sweating or erythema have been described. Respiratory signs such as tachypnea are sometimes noticed in the context of heart failure or simply associated with pulmonary arterial hypertension which can be documented by echocardiography. Sinus tachycardia is frequent, sometimes associated with cardiac arrhythmia, rarely with high blood pressure. Heart failure is one of the major risks in the neonate. Early diagnosis and treatment are required for a good prognosis. A congenital or neonatal infection should be excluded in the face of hepatomegaly, splenomegaly or polyadenopathy, which have been described in thyrotoxicosis, as have jaundice, cholestasis and thrombocytopenia. Abnormalities of liver function tests can occur even in the absence of cardiac insufficiency. A goiter is present in about $50 \%$ of the cases. Rarely, it leads to compression of the airways. Thyroid volume is best evaluated by echography. Traditionally, stare and eyelid retraction have been linked to thyrotoxicosis per se and exophthalmia to the autoimmune process. However, exophthalmia can also occur in non-autoimmune neonatal hyperthyroidism [19]. The fontanels are small and bone maturation is often advanced, as a consequence of increased thyroid hormone action on fetal bone.

\section{Diagnosis of Congenital Hyperthyroidism}

\section{The Newborns}

In newborns that have signs suggestive of congenital hyperthyroidism, the diagnosis should be confirmed by the determination of the plasma levels of $\mathrm{T}_{4}, \mathrm{~T}_{3}$ and $\mathrm{TSH}$. Even if these are normal, they should be repeated 3-7 days later because of the possibility of the delayed appearance of hyperthyroidism. They should be interpreted taking into account the peculiarities of the reference ranges for thyroid hormone levels in the neonatal period. The presence of TSIs in cord blood may be predictive of the occurrence of neonatal thyrotoxicosis [3, 4, 25]. Once neonatal hyperthyroidism is confirmed, its autoimmune origin should be established by determining the levels of TSI. In practice, these are measured by inhibition of the binding of TSH to thyroid membranes, in a radioreceptor assay.

\section{The Fetus: New Signs for a New Patient}

A few cases of fetal hyperthyroidism related to maternal TSH-receptor antibodies have been described $[3,4]$. In the absence of maternal treatment with ATD, hyperthyroidism develops in the fetus during the 2 nd half of pregnancy. Fetal goiter on the sonogram is a valuable finding and is the best sign of fetal thyroid dysfunction [4]. Normative data on the size of the fetal thyroid gland according to gestational age have been reported [26].

In fetuses with goitre, the main clinical problem was to determine whether the cause is ATD given for maternal treatment, adequate to have normal maternal thyroid function but inadequate and excessive for the fetus and therefore responsible for fetal hypothyroidism or fetal thyroid stimulation by maternal Graves' disease IgGs responsible for fetal hyperthyroidism.

It is generally agreed that fetal FT4 levels correlate with maternal FT4 levels and that fetal euthyroidism can be achieved by maintaining maternal FT4 in the upper normal to mildly thyrotoxic range during ATD treatment. This was underlined in one of our study, as maternal FT4 levels in the three cases with extremely severe fetal hypothyroidism were in the normal range in one case and in the lower normal range in the two others [4]. Nevertheless, we mainly used a combination of the following maternal criteria (TRAK [TSH receptor binding antibodies] titre and ATD use and dosage) and fetal criteria (thyroid Doppler signal, fetal heart rate (FHR), and bone maturation) to distinguish between fetal hypothyroidism and hyperthyroidism. 
Table 3. Useful thoughts to take care of congenital Graves disease

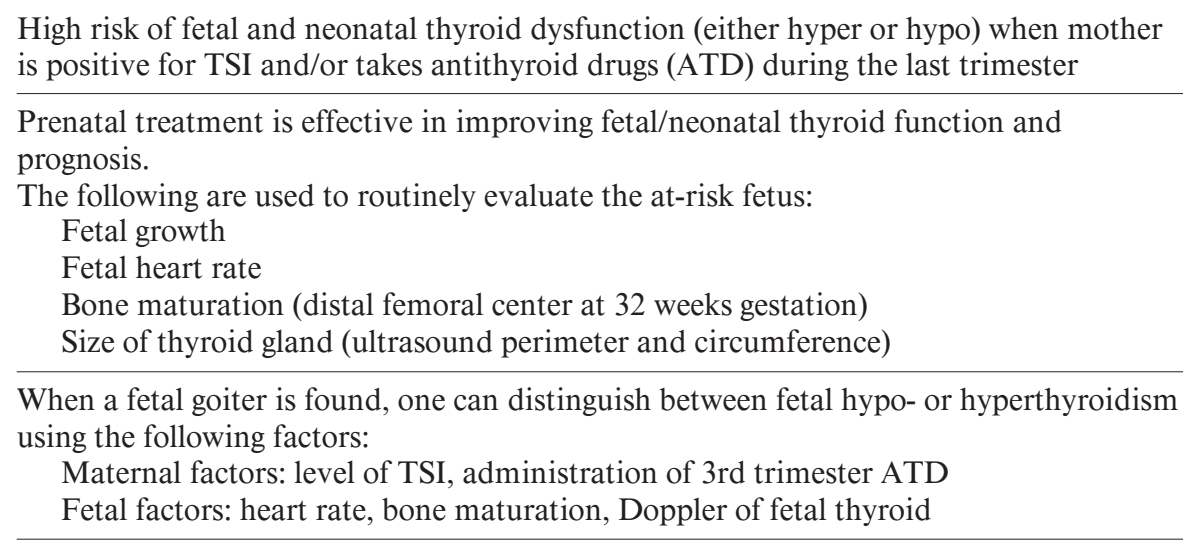

Fetal blood sampling should be reserved for those at risk of severe fetal hypothyroidism and when intra amniotic thyroxine injection is planned.

Cord blood thyroid hormone concentration does not predict postnatal hyperthyroidism but an elevated titer of TSI does.
Fetal blood sampling, the gold standard for the diagnosis of fetal thyroid dysfunction, should only be discussed after patient's agreement, and if there is a fetal goitre with no possibility to distinguish hypothyroidism and hyperthyroidism using maternal and fetal criteria. Fetal hyperthyroidism was diagnosed based on high maternal TRAK titres, accelerated fetal bone maturation, and a FHR greater than $160 \mathrm{bpm}$; this last sign was uncommon as it occurs late in the natural history of fetal hyperthyroidism. The limited usefulness of FHR for diagnosing fetal hyperthyroidism has been underlined also by Nachum et al. [27]. Doppler examination of the fetal thyroid gland proved useful only when the flash was confined to the periphery of the gland, a pattern suggestive of fetal hypothyroidism $[4,28]$. The prenatal response to treatment, results of thyroid function tests on fetal blood when obtained, and cord blood at birth indicated that our criteria were effective in differentiating hypothyroidism and hyperthyroidism in fetuses with goitre [4].

Fetal blood was sampled from 6 of the 11 fetuses with goitre, and the results consistently confirmed the suspected diagnosis [4]. Abortion, fetal bradycardia, and infection have been reported after FBS in 1\% of cases [29]. Consequently, FBS should be reserved for those cases in which the thyroid status is in doubt in a fetus whose mother has positive TRAK assays and takes ATD therapy or when intra-amniotic thyroxine injection is considered to treat potential ATD induced fetal hypothyroidism.

The results of routine cord blood assays of FT4 and TSH at delivery validated our prenatal strategy but did not help to predict subsequent neonatal thyroid dysfunction as already published [25].

\section{Treatment of and Outcome of Congenital Hyperthyroidism}

\section{Treatment of the Neonate}

Immediate treatment of overt neonatal hyperthyroidism is essential for a good prognosis [12]) (table 3). Propylthiouracil should be administered orally at a dose of $5-10 \mathrm{mg} / \mathrm{kg} /$ day divided in three doses. Compared to methimazole or carbimazole, it has the advantage that, in addition to blocking thyroid hormone secretion, it decreases the conversion of $\mathrm{T}_{4}$ to $\mathrm{T}_{3}$. A saturated solution of potassium iodide (SSKI) (1 drop/day) or Lugol's solution (1-3 drops/day) may be added in severe cases to decrease thyroglobulin proteolysis and thyroid hormone secretion. Propranolol promptly restores a normal heart rate. Other drugs, such as sodium iopanoate (iopanoic acid $500 \mathrm{mg}$ orally once every third day) and glucocorticoids, are seldom used to decrease thyroid hormone production and to inhibit $T_{4}$ to $T_{3}$ conversion [30]. Additional supportive measures, including high fluid and caloric intake, are essential.

In the immune mediated form, treatment should be maintained as long as the TSIs [or TRAK] are detectable, but not longer. It is often convenient to apply the 'block and replace' approach: a fixed dose of ATD is given, and thyroxine is added when plasma thyroxine reaches the 
Table 4. Strategy for the follow-up of pregnancies in mothers with Graves' disease based on our work $[3,4,12,28$, 34]

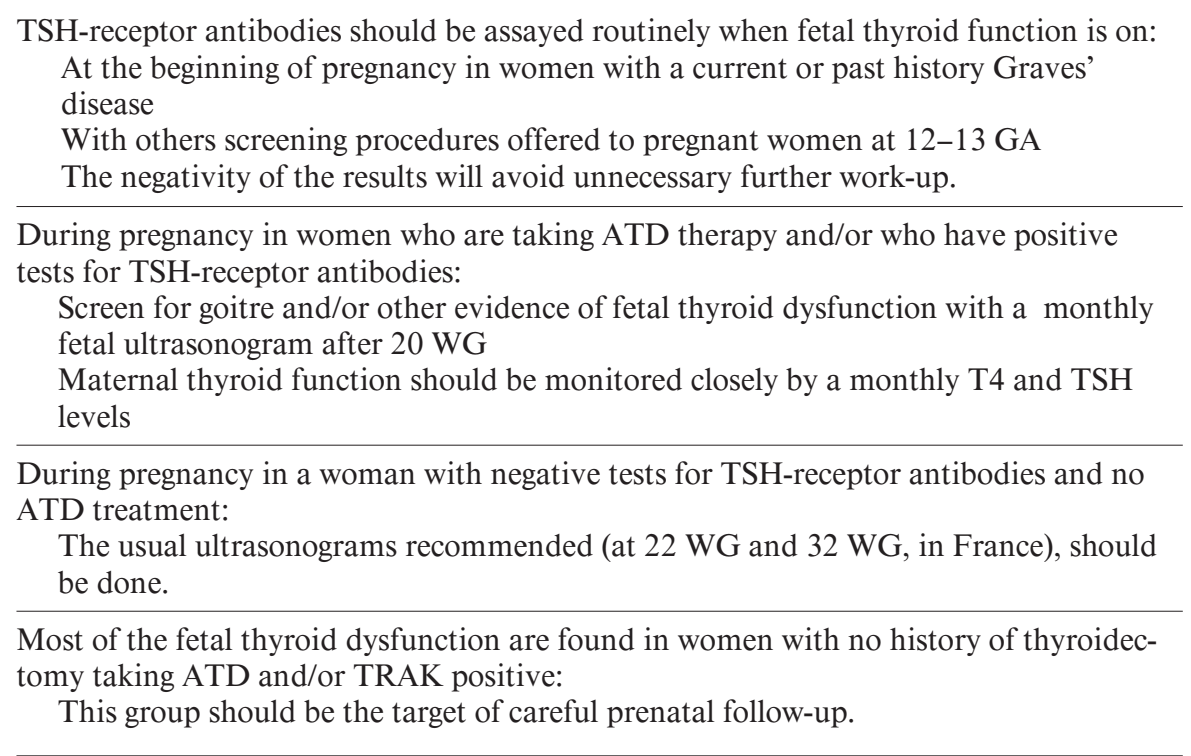

hypothyroid range. On average, treatment is required for 1 month [3]. Even though it is transient, symptomatic neonatal hyperthyroidism should be treated to avoid both short-term (heart failure) and long-term morbidity (craniosynostosis, intellectual impairment).

It should also be remembered that central congenital hypothyroidism of the newborn has also been described with gestational hyperthyroidism [31]. Because all mothers were insufficiently treated during pregnancy, it was hypothesized that a hyperthyroid fetal environment impaired the maturation of the fetal hypothalamic-pituitary and thyroid system [31].

\section{Treatment of the Fetus for Hyper-and/or}

Drug-Induced Hypothyroidism

Treatment of the fetus by administrating ATD to the mother has been shown to improve fetal and neonatal prognosis. In pregnant women, propylthiouracil is preferred over methimazole because of reports that MMI may be associated with aplasia cutis congenita and other malformations [32].

Because ATDs cross the placenta, hypothyroidism can also occur in fetuses borne by women on ATD therapy for Graves' disease. The diagnosis can be suggested by ultrasound visualization of fetal goiter and confirmed by tests on fetal blood samples. Because thyroid hormones play a crucial role in fetal brain development, fetal hypothyroidism can cause permanent intellectual impairment. ATD dosage reduction should be effective in restoring normal fetal thyroid function but the use of intra-amni- otic thyroxine injection has been reported [4]. Fetal blood sampling should be reserved for those cases in which intra-amniotic thyroxine injection is considered or when the thyroid status is in doubt in a fetus whose mother has positive TSI and takes ATD therapy. Thus, fetuses of mothers on ATD therapy can develop either hypo- or hyperthyroidism. Early diagnosis and treatment of fetal hyperthyroidism are crucial to prevent premature delivery, death in utero, or permanent neurological impairment.

In pregnant women with a current or past history of Graves' disease, we believe that TSI should be assayed routinely at the beginning of pregnancy, at variance with the European Thyroid Association 1998 guidelines [33]. In pregnant women who are taking ATD therapy and/or have positive TSI, monthly ultrasounds after 20 weeks of gestation to detect the development of goiter and/or other evidence of thyroid dysfunction in the fetus may be justified [4]. It should also be remembered that fetal hyperthyroidism can occur in fetuses borne by women who have actually become hypothyroid after thyroid ablation for Graves's disease and are on thyroxine replacement, if they have persistently elevated levels of TSIs. In pregnant women with a history for Graves' disease but negative TSI and no ATD treatment, routine prenatal care suffices, specially as their thyroid function will adapt normally to pregnancy [34] (table 4).

\section{Long-term Outcome of Congenital Hyperthyroidism}

Since the historical descriptions of craniosynostosis and developmental delay after recovery from transient 
neonatal hyperthyroidism [35], there have been very few studies of long-term developmental outcome of these patients. In one study, no difference in growth or psychomotor development was found at age 7-8 years between children born to mothers with treated hyperthyroidism and children born to euthyroid mothers [36]. If neuropsychological sequelae are noted, they may be difficult to disentangle form those of prematurity per se [37]. With this caveat, it seems that an optimistic long-term prognosis can be given to the parents of neonates with Graves' disease.

\section{Conclusions}

Prenatal screening ultrasonography is a powerful tool for detecting fetal thyroid dysfunction. Ultrasonographic monitoring, by an expert radiologist, of fetuses from mothers with Graves' disease was extremely sensitive and specific for detecting intrauterine thyroid dysfunction and therefore allowed appropriate fetal management.
This tool, in conjunction with close teamwork among internists, endocrinologists and obstetricians, echographists and pediatrician, can ensure normal fetal thyroid function. Neonates should be managed in centers used to treat these types of disorders. The fetus has become our patient!

\section{Acknowledgements}

We thank all the families who participated in our studies and physicians who helped us to conduct our work in this field: Michèle Noel MD, Department of Biochemistry and Hormonology, Robert Debré Hospital, Marie-Elisabeth Toubert MD and Marie Hélène Schlageter MD, Department of Nuclear Medicine, Saint Louis Hospital, Catherine Garel MD, Department of Radiology, Robert Debré Hospital, Christine Boissinot MD, Brigitte Tebeka MD and Jean-François Oury MD, Department of Perinatology, Multidisciplinary Center for Prenatal Diagnosis EA3102, Robert Debré Hospital, Juliane Léger MD and Paul Czernichow MD, Department of pediatric Endocrinology and Diabetology, Robert Debré Hospital, all in Paris, France.

\section{References}

1 Anselmo J, Cao D, Karrison T, Weiss RE, Refetoff S: Fetal loss associated with excess thyroid hormone exposure. JAMA 2004;292: 691-695.

-2 Kopp P, Van Sande J, Parma J, Duprez L, Gerber H, Joss E, et al: Brief report: congenital hyperthyroidism caused by a mutation in the thyrotropin-receptor gene. N Engl J Med 1995; 332:150-154.

>3 Polak M, Le Gac I, Vuillard E, Guibourdenche J, Leger J, Toubert ME, et al: Fetal and neonatal thyroid function in relation to maternal Graves' disease. Best Pract Res Clin Endocrinol Metab 2004;18:289-302.

$\checkmark 4$ Luton D, Le Gac I, Vuillard E, Castanet M, Guibourdenche J, Noel M, et al: Management of Graves'disease during pregnancy: the key role of foetal thyroid gland monitoring. J Clin Endocrinol Metab 2005;90:6093-6098.

$\checkmark 5$ De Felice M, Di Lauro R: Thyroid development and its disorders: genetics and molecular mechanisms. Endocr Rev 2004;25:722-746.

6 Polak M, Sura-Trueba S, Chauty A, Szinnai G, Carre A, Castanet M: Molecular mechanisms of thyroid dysgenesis. Horm Res 2004;62(suppl 3):14-21.

7 Olin P, Vecchio G, Ekholm R, Almquist S: Biosynthesis of thyroglobulin related to the ultrastructure of the human fetal thyroid gland. Endocrinology 1970;86:1041-1048.
Shepard TH: Onset of function in the human fetal thyroid: biochemical and radioautographic studies from organ culture. J Clin Endocrinol Metab 1967;27:945-958.

9 Szinnai G, Lacroix, Guimiot F, Talbot M, Martinovic J, Delezoide AL, Vekemans M, Michiels S, Caillou B, Schlumberger M, Bidart JM, Polak M: Ontogeny of thyroid function in the human fetus: the sodium/iodide symporter (NIS) is the gatekeeper of thyroid hormone synthesis. LWPES/ESPE Lyon 21-24 sept 2005; Horm Res 2005;64(suppl):355-1224.

10 Vulsma T, Gons MH, de Vijlder JJ: Maternalfetal transfer of thyroxine in congenital hypothyroidism due to a total organification defect or thyroid agenesis. N Engl J Med 1989;321: 13-16.

-11 Morreale de Escobar G, Obregón MJ, Escobar del Rey F: Is neuropsychological development related to maternal hypothyroidism or to maternal hypothyroxinemia? J. Clin. Endocrinol. Metab 2000;85:3975-3987.

12 Polak M: Hyperthyroidism in early infancy: pathogenesis, clinical features and diagnosis with a focus on neonatal hyperthyroidism. Thyroid 1998;8:1171-1177.

13 Davies TF, Ando T, Lin RY, Tomer Y, Latif $\mathrm{R}$ : Thyrotropin receptor-associated diseases: from adenoma to Grave disease. J Clin Invest 2005;115:1972-1983.

14 Zakarija M, McKenzie JM: Pregnancy-associated changes in the thyroid-stimulating antibody of Graves' disease and the relationship to neonatal hyperthyroidism. J Clin Endocrinol Metab 1983;57:1036-1040.
$>15$ Brown RS, Bellisario RL, Botero D, Fournier $\mathrm{L}$, Abrams CA, Cowger ML, et al. Incidence of transient congenital hypothyroidism due to maternal thyrotropin receptor-blocking antibodies in over one million babies. J Clin Endocrinol Metab 1996;81:1147-1151.

16 Hollingsworth DR, Mabry CC, Eckerd JM: Hereditary aspects of Graves' disease in infancy and childhood. J Pediatr 1972;81:446459.

17 Thomas JS, Leclere J, Hartemann P, Duheille J, Orgiazzi J, Petersen M, et al. Familial hyperthyroidism without evidence of autoimmunity. Acta Endocrinol (Copenh) 1982;100:512518.

$>18$ Duprez L, Parma J, Van Sande J, Allgeier A, Leclere J, Schvartz C, et al: Germline mutations in the thyrotropin receptor gene cause non-autoimmune autosomal dominant hyperthyroidism. Nat Genet 1994; 7:396-401.

19 de Roux N, Polak M, Couet J, Leger J, Czernichow P, Milgrom E, et al: A neomutation of the thyroid-stimulating hormone receptor in a severe neonatal hyperthyroidism. J Clin Endocrinol Metab 1996;81:2023-2026.

20 Yoshimoto M, Nakayama M, Baba T, Uehara Y, Niikawa N, Ito M, et al: A case of neonatal McCune-Albright syndrome with Cushing syndrome and hyperthyroidism. Acta Paediatr Scand 1991;80:984-987. 
21 Shenker A, Weinstein LS, Moran A, Pescovitz $\mathrm{OH}$, Charest NJ, Boney CM, et al: Severe endocrine and nonendocrine manifestations of the McCune-Albright syndrome associated with activating mutations of stimulatory $\mathrm{G}$ protein GS. J Pediatr 1993;123:509-518.

-22 Leclere J, Bene MC, Aubert V, Klein M, Pascal-Vigneron V, Weryha G, et al: Clinical consequences of activating germline mutations of TSH receptor, the concept of toxic hyperplasia. Horm Res 1997;47:158-162.

-23 Duprez L, Parma J, Van Sande J, Rodien P, Sabine C, Abramowicz M, et al: Pathology of the TSH receptor. J Pediatr Endocrinol Metab 1999;12(suppl 1):295-302.

-24 Kopp P, Muirhead S, Jourdain N, Gu WX, Jameson JL, Rodd C: Congenital hyperthyroidism caused by a solitary toxic adenoma harboring a novel somatic mutation (serine281->isoleucine) in the extracellular domain of the thyrotropin receptor. J Clin Invest 1997; 100:1634-1639.

>25 Skuza KA, Sills IN, Stene M, Rapaport R: Prediction of neonatal hyperthyroidism in infants born to mothers with Graves disease. J Pediatr 1996;128:264-268.
26 Ranzini AC, Ananth CV, Smulian JC, Kung M, Limbachia A, Vintzileos AM: Ultrasonography of the fetal thyroid: nomograms based on biparietal diameter and gestational age. J Ultrasound Med 2001;20:613-617.

27 Nachum Z, Rakover Y, Weiner E, Shalev E: Graves' disease in pregnancy: prospective evaluation of a selective invasive treatment protocol. Am J Obstet Gynecol 2003;189:159_ 165.

28 Luton D, Fried D, Sibony O, Vuillard E, Tebeka B, Boissinot C, Leger J, Polak M, Oury JF, Blot P: Assessment of fetal thyroid function by colored Doppler echography. Fetal Diagn Ther 1997;12:24-27.

29 Daffos F, Capella-Pavlovsky M, Forestier F: Fetal blood sampling during pregnancy with use of a needle guided by ultrasound: a study of 606 consecutive cases. Am J Obstet Gynecol 1985; 153:655-656.

30 Transue D, Chan J, Kaplan M: Management of neonatal Graves disease with iopanoic acid. J Pediatr 1992;121:472-474.

31 Kempers MJE, Van Tijn DA, Van Trotsenburg PAS, De Vijlder JJM, Wiedijk BM, Vulsma T: Central congenital hypothyroidism due to gestational hyperthyroidism: detection where prevention failed. J Clin Endocrinol Metab 2003; 88:5851-5857.
32 Foulds N, Walpole I, Elmslie F, Mansour S: Carbimazole embryopathy: an emerging phenotype. Am J Med Genet 2005;132:130-135.

33 Laurberg P, Nygaard B, Glinoer D, Grussendorf M, Orgiazzi J: Guidelines for TSH-receptor antibody measurements in pregnancy: results of an evidence-based symposium organized by the European Thyroid Association. Eur J Endocrinol 1998;139:584-586.

34 Luton D, Le Gac I, Noel M, Guibourdenche J, Polak M: Thyroid Function during Pregnancy in Women with Past Graves' disease. Br J Obstet Gynaecol 2005;112:1565-1567.

35 Daneman D, Howard NJ: Neonatal thyrotoxicosis: intellectual impairment and craniosynostosis in later years. J Pediatr 1980;97:257259.

36 Messer PM, Hauffa BP, Olbricht T, Benker G, Kotulla P, Reinwein D: Antithyroid drug treatment of Graves' disease in pregnancy: longterm effects on somatic growth, intellectual development and thyroid function of the offspring. Acta Endocrinol (Copenh) 1990; 123:311-316.

37 Smith C, Thomsett M, Choong C, Rodda C, McIntyre HD, Cotterill AM: Congenital thyrotoxicosis in premature infants. Clin Endocrinol (Oxf) 2001;54:371-376. 